\title{
Introduction to the Special Issue on the Impact of Network Ethics on Business Practices
}

\author{
Antonino Vaccaro \\ Adele Santana \\ Donna J. Wood
}

\begin{abstract}
This special issue on network ethics offers 15 scholarly articles from a variety of disciplines and fields of study, all aimed at exploring some important aspect of how networks develop, enact, and enforce ethical norms. The articles are ordered according to the levels of analysis each deals with, ranging from the cognitive/intrapersonal to the systemic/societal. Taken together, these articles provide a fresh look at how networks are changing the way business is done and the way we think about ethics.
\end{abstract}

KEY WORDS: network, business ethics, information ethics, interorganizational relationships, virtue ethics, justice, social networks, supply chain, fair trade

During the last few decades, the idea of network as a set of interconnected actors has proven to be an appealing and reliable conceptual tool for the analysis of problems both in management and in economics. The idea underlying this special issue is that the use of the new conceptual lenses offered by the theory of networks can offer a new understanding in the fields of $\mathrm{BE}$ and corporate social responsibility (CSR). Indeed, normative and descriptive theories in $\mathrm{BE}$ and CSR are founded on the concept of social network as embodied in stakeholder theory, based on the assumption that a company should be accountable to all the individuals, groups, and organizations that affect or are affected by its activities. Looking from this standpoint, BE discourse should focus on analysis of the relationships of companies and individuals "being interconnected" or "being networked". As Melé argues in this issue, network interactions are voluntary and it is reasonable to expect that these interactions are ethical.
In this context, the network standpoint becomes particularly important if we reflect on the impact that information and communication technologies (ICTs) have on individuals and groups at intra- and inter-organizational levels. In both cases, what matters is that each person acknowledges the effects of "being networked" with others on his/her life and behavior. This consideration opened the door to a second important issue that ignited many discussions among the editors of this special issue: The emergence of digital networks, as opposed to traditional or "non-virtual" networks, is causing a progressive convergence between two disciplines that were originally quite distant, i.e., BE and computer ethics. Indeed, Deborah G. Johnson has recently argued that "corporations don't use their information technology, they are their information technology" (Johnson, 2006, pp. 457-458). In other words, the progressive virtualization of business and social activities is shifting the domain of social interaction, and consequently business activities, from the physical to the virtual. For example, recent studies have shown that the degree of social interconnectivity has exploded during the last 10 years, allowing individuals in developed countries to interact through internet-based technologies with friends, colleagues, and peers who are thousands of miles distant (see, e.g. Barabási, 2002).

This sociological modification has important consequences for how we should look at and analyze BE questions. Indeed, virtual technologies have driven the "re-ontologization" of human society and how individuals and organizations behave and interact (see, e.g. Floridi, 1999, 2007). As a consequence, several themes that had a central importance in the debate of computer ethicists during the 1960s 
and 1970s (e.g., privacy, information reliability, availability, security, etc.) are now important issues as well for BE scholars, managers, and policy makers. We believe that this special issue shows that a network ethics framework can play a crossroads role for computer ethics, information ethics, and business ethics.

Along this same line, the journal Ethics and Information Technology published in 2009 a special issue on organizational transparency, an important problem domain in the ethics of social networks (see, e.g. Vaccaro and Madsen, 2009a, b). That special issue contained contributions from computer ethics, information ethics, and BE scholars (see, e.g. Elia, 2009; Santana and Wood, 2009; Turilli and Floridi, 2009).

This special issue of the Journal of Business Ethics moves another step forward. It shows that a network ethics approach facilitates convergence of themes among these disciplines. This issue is composed of 15 articles, representing a rich and diverse selection of scholarly work. Taken together, the articles in this special issue address virtually every level of analysis, beginning with the intra-individual/cognitive level; passing through the individual, individual-network, organizational, and organizational-stakeholder network or interorganizational network levels; and culminating with the systemic/societal/intersocietal level of analysis (see Table I). This comprehensive span allows the reader to formulate questions, hypotheses, and propositions that take into account the embeddedness of any particular phenomenon in multiple levels of analysis. In addition, the 15 articles collectively deal with a wide variety of units of analysis, including systems, networks, sub-networks, online business communication, peer-to peer software, the organization, the organization-stakeholder relationship, the manager, and even cognitive units such as beliefs and principles. Finally, there is a healthy mix of conceptual/theoretical and empirical approaches.

George Bragues' piece on “Adam Smith's Vision of the Ethical Manager" analyzes Smith's moral thought by adopting a social networks perspective on how individual managers should act. Bragues shows that Smith's prescriptive self-interest motive

\section{TABLE I}

Levels of analysis in the special issue

\begin{tabular}{|c|c|c|c|c|c|c|}
\hline \multirow[t]{2}{*}{ Authors } & \multicolumn{6}{|c|}{ Level of analysis } \\
\hline & $\begin{array}{l}\text { Cognitive } \\
\text { (intra-individual) }\end{array}$ & Individual & $\begin{array}{l}\text { Network } \\
\text { of individuals }\end{array}$ & Organizational & $\begin{array}{c}\text { Interorgani- } \\
\text { zational } \\
\text { network }\end{array}$ & System \\
\hline Bragues & $x$ & $x$ & & & & \\
\hline Bagozzi, Sekerka, and Hill & $x$ & $x$ & & & & \\
\hline Melé & & $x$ & $x$ & & & \\
\hline Grabner-Kräuter & & $x$ & $x$ & & & \\
\hline Chen & & $x$ & $x$ & $x$ & & \\
\hline Logsdon and Patterson & & $x$ & $x$ & $x$ & & \\
\hline Pagallo and Durante & & $x$ & $x$ & $\times$ & & \\
\hline Millar and Choi & & & $x$ & $x$ & $x$ & \\
\hline $\begin{array}{l}\text { Burchielli, Delaney, Tate, } \\
\text { and Coventry }\end{array}$ & & & $x$ & $x$ & $x$ & \\
\hline $\begin{array}{l}\text { Özçağlar-Toulouse, Béji-Bécheur, } \\
\text { and Murphy }\end{array}$ & & & $x$ & $x$ & $x$ & \\
\hline Vurro, Russo, and Perrini & & & & $x$ & $x$ & \\
\hline Garriga & & & & $x$ & $x$ & \\
\hline Madsen & & & & $x$ & $x$ & \\
\hline Floridi & & & $x$ & $x$ & $x$ & $x$ \\
\hline Santana, Vaccaro, and Wood & & $x$ & $x$ & $\times$ & $x$ & $x$ \\
\hline
\end{tabular}


can and should be subordinated to moral imperatives, even in business networks, and that the modern focus on "profits above all" is in fact out of line with Smith's concept of the virtuous manager. Indeed, according to Smith, an ideal manager should address the standards enforced by an "impartial spectator" of his/her conduct, which in turn is an abstract entity reflecting the ethical requirements posed by social networks. Bragues argues that a network perspective on Smith's works points to the importance of justice and prudence in managerial decision-making processes. (We will see these two ethical themes together again in Madsen's article in the special issue.)

Using a mixed-method approach, Richard P. Bagozzi, Leslie Sekerka, and Vanessa Hill take the notion of moral motives into the cognitive structures of leader-managers by applying mathematical network analysis to an empirical study of moral decision making in their article, "Hierarchical Motive Structures and Their Role in Moral Choices." From a sample of 101 managers in the U.S. military, the authors empirically identify 16 motives to act morally, and more importantly, they are able to show the cognitive linkages among these motives. The authors found that some reasons for action take precedence over others, in a hierarchy of linked motives that builds from the concrete to the abstract. Ethical motives and how they relate to each other are depicted in a cognitive map, in effect displaying a cognitive conceptual network. The depicted conceptual relationships are theoretically associated with virtue ethics, consequentialism, deontological theories, and 'emotional empiricism'.

The virtue ethics theme, with its emphasis on the individual level of analysis but bridging to networks of individuals, continues with Domènec Melé's article on "The Practice of Networking: An Ethical Approach." Melé analyzes the practice of business networking by first proposing a three-category taxonomy of network practices: utilitarian, emotional, and virtuous. The article then provides detailed arguments on the differences between a virtuous and an immoral network practice. In particular, according to the author, virtuous networking requires acting with good faith; sharing honest goals; participating in licit activities; sharing information, knowledge, and resources with reciprocity and even with gratuity; serving with justice in asymmetrical power relationships; and exercising a positive ethical influence within the network. By contrast, unethical behavior in networking practice is marked by bad faith or abuse of trust, opportunism, abuse and misuse of power, cronyism, networking as disguised bribery, and cooperating in the wrongdoing of other actors of the network.

In "Web 2.0 Social Networks: The Role of Trust," Sonja Grabner-Kräuter makes explicit the link between individual ethics and network ethics by examining the role of trust in online social networks (e.g., Facebook, LinkedIn, MySpace). In particular, the article examines the structural and relational underpinnings of trust in online social networks by looking at governance issues and social network perspectives. Why do participants initially choose to trust, and how does trust actually emerge in social network interactions? The article points out that the relationship between social capital and trust is not unidirectional, as implied in previous literature, but it is instead reciprocal as well as multi-dimensional. The author develops a theoretical discussion and related propositions on the environmental, cognitive, and relational correlates of trust in virtual social networks.

The next article, "Corporate Responsibilities in Internet-Enabled Social Networks" by Stephen Chen, continues with the Web 2.0 social networking theme but expands the discussion of network governance into inter-organizational as well as interpersonal networks. Chen shows how social network theory can be used to determine corporate responsibilities, both direct and indirect, in internetenabled social networks. The article examines corporate responsibilities based on four key network features: relational properties, individual properties, subgroup properties, and total network properties. The article also presents some important implications for managers, policy makers, and some interesting perspectives for further research.

In "Deception in Business Networks: Is It Easier to Lie Online?", Jeanne M. Logsdon and Karen D. W. Patterson turn our attention from virtue and responsibility to the dark side of network behavior. They propose a theoretical model that identifies critical factors affecting the propensity to deceive in online business communication. Drawing from a variety of relevant sources, the authors propose four variables that increase individuals' propensity to 
deceive (weak ties, asymmetrical emotional relationships, differential power relationships, and decreased proximity), and three critical factors that mitigate deception in networks (structural holes, density, and probability of effect). The article also provides policy recommendations on how to prevent, identify, and discourage deception in online business networks, and it proposes new avenues of research to extend our understanding of deceptive behavior in virtual networks.

The article by Ugo Pagallo and Massimo Durante, "Three Roads to P2P Systems and Their Impact on Business Practices and Ethics," presents an analysis of peer-to-peer (P2P) software based on three different perspectives. The first perspective, the topological approach, analyzes the 'short route' processes of information generation and distribution which emerge with P2Ps. The second perspective analyzes P2P through a context-based approach and identifies the norms governing informational flows. The third perspective is based on Floridi's information ethics theory and provides an analysis of $\mathrm{P} 2 \mathrm{P}$ impact on the infosphere. P2P software is controversial, of course, because it allows users to share copyrighted content (music, books, etc.) without paying royalties. The authors thus offer key insights into the debate over whether information-sharing rights outweigh content ownership rights and whether - and how $-\mathrm{P} 2 \mathrm{P}$ software should be regulated.

The article by Carla Millar and Chong Ju Choi, titled "Networks, Social Norms and Knowledge Sub-Networks," continues the focus on information-sharing by analyzing how knowledge, at both tacit and explicit levels, can be transferred and exchanged through virtual networks. The article introduces and develops the concept of subnetworks, a locus where tacit knowledge can be transferred through the support of reliable and clear social norms underlying trust and other informal mechanisms. The authors also explain how the subnetwork construct can complement traditional theories that analyze knowledge transfer and exchange based on marketplace exchange and property rights.

Next comes an empirical article by Rosaria Burchielli, Annie Delaney, Jane Tate, and Kylie Coventry: "The Fair Wear Campaign: An Ethical Network in the Australian Garment Industry." In many parts of the world, home-work is part of an underground economy, unregulated, precarious, invisible, and too often exploitative. The authors examine the operations of a fair trade network in Australia, operating on principles of justice for workers, and they illustrate the challenges and opportunities of such networks for ethical supply chain management and corporate social responsibility. The article shows how the Australian FairWear Campaign, a community network alliance focused on the battle against sweatshops, developed norms and actions to fight the exploitation of homeworkers in the Australian garment industry and to improve their wages and working conditions.

Fair trade networks have sprung up around the world, and in the next article, "Fair Trade in France: From Individual Innovators to Contemporary Networks," we see one in operation in a developed European nation. The authors, Nil ÖzçağlarToulouse, Amina Béji-Bécheur, and Patrick E. Murphy, provide an interview-based analysis of the fair trade sector in France which encompasses firms operating in very diverse industries such as textile, fashion, food, cosmetics, etc. The article shows that there are "other" bottom lines for participants in these fair trade networks: the members are by and large social entrepreneurs, interested in service, social justice, and a "solidarity economy" along with profit. The authors extend current literature on network ethics and theory by identifying some critical variables that characterize fair trade networks in France, i.e., trust, commitment, equity, and informational transparency. The importance and difficulty of certification in fair trade networks is emphasized.

The supply chain angle of network ethics continues as Clodia Vurro, Angelo Antonio Russo, and Francesco Perrini present a theoretical argument that identifies four sustainable supply chain governance (SSCG) models. Their article, "Shaping Sustainable Value Chains: Network Determinants of Supply Chain Governance Models," shows that these four SSCG types are the result of different combinations of supply chain network densities and degrees of centrality of the focal organization in the network. The article also shows that higher centrality supports higher capability of a firm to exert influence over its network, coordinating integrated approaches along the value chain. The article also explores some conditions for the success of SSCGs and identifies some benefits that can be obtained by firms in different network positions. 
Elizabeth Garriga broadens the domain from supply chain to more general firm-stakeholder relationships, using a case study of "Gas-Nat," an Argentinean natural gas provider, to analyse cooperation processes in complex interorganizational networks. Her article, "Cooperation in Stakeholder Networks: Firms' 'Tertius Iungens' Role,' builds a stakeholder cooperation model based on both structural factors (stakeholder's position) and relational factors (framing process and political opportunity structure). She shows that, contrary to the propositions in stakeholder network literature that structure determines action, and that the firm has the role of tertius gaudens - a self-interested broker - in the network, effective cooperation processes result from a firm's adoption of the tertius iungens role - an arbiter in the network - where the focal firm works actively to connect and unite different kinds of stakeholders.

Peter Madsen brings our attention back to virtue ethics and justice (and also to the ideas of Adam Smith) in his article, "Dynamic Transparency, Prudential Justice, and Corporate Transformation: Becoming Socially Responsible in the Internet Age." Focusing on firms' relationships with their stakeholder networks, he argues that prudential justice is the set of underlying values that support dynamic transparency in a company's communication with stakeholders. Dynamic transparency is achieved through the use of Internet-based tools and refers to the multidirectional interactive flow of information in complex stakeholder networks. The concept of prudential justice aims at bridging individual (prudence) and societal (justice) levels of ethical analysis through the level of organizational action; it provides a solid rationale for managers to act simultaneously with self-interest and self-regard, and with the interests of all stakeholders in mind. The article has practical implications for managers, and the author offers guidelines for acting with prudential justice.

Luciano Floridi's article, "Network Ethics: Information and Business Ethics in a Networked Society," presents an informational approach to the conceptual foundation of business ethics. Floridi proposes the application of information ethics theory as an alternative and complementary approach to $\mathrm{BE}$ issues. Using information ethics methodology to model foundational aspects of $\mathrm{BE}$ in our networked society, Floridi discusses the nature of moral agents, the receivers of moral actions, the environment, and moral relations and interactions, and he offers a framework that interprets BE informationally. One of the interesting conclusions from his analysis is that in business, the nature of business agents, the fairness of prices, and the level of profits are of less importance than the nature of goods or services produced, the way they are produced, and their impact on the environment. The article provides perspectives for further research in the literature of business ethics, computer ethics, and information ethics and for a more interdisciplinary analysis of ethical issues in business and society.

Finally, the article authored by Adele Santana, Antonino Vaccaro, and Donna J. Wood, "Ethics and the Networked Firm," explores the influence of a key perceptual dimension - how a firm is viewed on the typical processes that managers use. The perceptual dimension examined contrasts the traditional closed-system mechanistic rational view of the firm with the view of a firm as open-system, organic and probabilistic. Pushing through a logical continuum of open-systems views, necessarily changes the image of a firm from a strongly bounded entity to a configuration of networks and sub-networks that exists and operates in a larger systemic network configuration. The authors propose four classes of managerial processes corresponding to particular views of the firm along the closed/open-systems continuum, along with three transitional classes. The final class of management processes focuses on the achievement of outcomes that are mutually satisfactory in the set of networks and sub-networks that constitute the focal firm, as well as the sustainability of the whole system. The authors propose that particular kinds of ethical problems will tend to arise in firms where particular classes of management processes are dominant.

Earlier versions of some articles in this special issue were presented at the Conference "Network Ethics: The New Challenge in Business, ICT and Education," hosted by the Center for Ethics, Business and Economics of the School of Business and Economics of the Catholic University of Portugal, in collaboration with Carnegie Mellon University and the University of Northern Iowa. Although we would like to thank all the people who contributed to the conference and to the edition of this special issue, the authors would especially thank Peter Madsen, 
João César das Neves, and João Seabra. Special thanks go to Farzad Moussavi, the Dean of the College of Business Administration at the University of Northern Iowa, for his continuous support during the development of this three-year project. We would finally thank our sponsors and in particular: Fundação para a Ciência e a Tecnologia (Portugal), Carnegie Mellon University, the Cylab (Carnegie Mellon University), the University of Northern Iowa's College of Business Administration and the David W. Wilson Chair in Business Ethics, and the Dean's office of the School of Business and Economics of the Catholic University of Portugal.

Reviewing for this issue was especially difficult because of the need to assure field-specific accuracy and relevance as well as broad appeal to a general audience of intelligent readers. The following colleagues contributed reviews, and we are very grateful for the time and effort they put into this important work: Anthony Beavers, Elizabeth Buchanan, Jerry Calton, Tara Ceranik, Francis Degnin, Craig Dunn, Massimo Durante, Heather Elms, Charles Ess, Sefa Hayibor, Vanessa Hill, Michael Johnson-Cramer, Scott Kelley, Maryellen Kelly, Jaehwan Lee, Jeanne Logsdon, William Martello, Jim Mattingly, Scott Paeth, Tara Radin, Leslie Sekerka, Miguel Sicart, Johnny Hartz Søraker, Kelly Strong, Mariarosaria Taddeo, Harry Van Buren, and Patricia Werhane.

\section{References}

Barabási, A. L.: 2002, Linked: How Everything is Connected to Everything Else (Plume/Penguin Group, New York, NY).

Elia, J.: 2009, 'Transparency, Rights, Technology and Trust', Ethics and Information Technology 11(2), 145153.

Floridi, L.: 1999, 'Information Ethics: On the Philosophical Foundations of Computer Ethics', Ethics and Information Technology 1(1), 37-56.
Floridi, L.: 2007, 'A Look into the Future Impact of ICT on Our Lives', The Information Society 23(1), 59-64.

Johnson, D.: 2006, 'Corporate Excellence, Ethics and the Role of IT', Business and Society Review 111(4), 457475.

Santana, A. and D. J. Wood: 2009, 'Information vs. Knowledge: Transparency and Social Responsibility Issues for Wikipedia', Ethics and Information Technology 11(2), 133-144.

Turilli, M. and L. Floridi: 2009, 'The Ethics of Information Transparency', Ethics and Information Technology 11(2), 105-112.

Vaccaro, A. and P. Madsen: 2009a, 'Corporate Dynamic Transparency: The New ICT-Driven Ethics?', Ethics and Information Technology 11(2), 113-122.

Vaccaro, A. and P. Madsen: 2009b, 'Transparency in Business and Society: Introduction to the Special Issue', Ethics and Information Technology 11(2), 101-103.

Antonino Vaccaro

IESE, University of Navarra, Barcelona, Spain E-mail: avaccaro@iese.edu

and

FCEE, Catholic University of Portugal, Lisbon, Portugal

Adele Santana

University of Northern Iowa, Cedar Falls, IA 50614, U.S.A.

E-mail: adele.santana@uni.edu

Donna J. Wood

The David W. Wilson Chair in Business Ethics, University of Northern Iowa, Cedar Falls, IA 50614, U.S.A. E-mail:donna.wood@uni.edu 